\title{
MOBILIDADE CULTURAL E MOBILIZACIÓN POLÍTICA: DINÁMICAS TRANSNACIONAIS, ACCIÓN NACIONAL
}

Joep Leerssen

Universiteit van Amsterdam

DOI: 10.17075/iftpc.2021.001 

wie es eigentlich gewesen: wahnsinnig kompliziert

(á maneira de Ranke)

\section{NACIONALISMO TRANSNACIONAL E NACIONALISMO METODO- LÓXICO (SOMME, DUBLÍN, A CORUÑA)}

O ano 1916 conmemórase en Irlanda por dous motivos e no seo de dúas comunidades mnemónicas: por unha banda, os protestantes do Ulster lembran a batalla da Somme, que inflixiu unha altísima cifra de baixas entre, sobre todo, os rexementos daquela provincia irlandesa, e, pola outra, na historia do nacionalismo irlandés, a data evoca o Alzamento de Pascua, cando un grupo de activistas culturais radicalizados procedentes da Liga Gaélica e dos Voluntarios Irlandeses ocupou puntos estratéxicos da capital, Dublín, e proclamou unha República Irlandesa independente. Nunha zona de Europa totalmente distinta, A Coruña, ese mesmo ano tivo lugar un acto constitutivo: a fundación das Irmandades da Fala.

A simultaneidade e as correlacións que se deron entre estes tres acontecementos, dispares e disímiles, resultan intrigantes en varios aspectos. Neste sentido, ningún de tales sucesos pode entenderse agás en relación inmediata co outro e, en consecuencia, en relación intermedia co terceiro. Os voluntarios do Ulster que se alistaran no Exército Británico fixérano, en moitos casos, para demostraren o seu unionismo, é dicir, o seu rexeitamento a formaren parte dun plan de goberno local para Irlanda que houbo entrar en vigor de non ser polo estoupido da Gran Guerra; os insurrectos irlandeses conseguían armas de Alemaña e actuaban de acordo co arraigado principio de que «a dificultade de Inglaterra é 
a oportunidade de Irlanda», e todas as achegas a este volume deixan meridianamente claro ata que punto a Liga Gaélica e o rexurdimento irlandés constituíron unha fonte de inspiración e un marco de acción para as Irmandades da Fala.

Á inversa, a sincronía e as fortes implicacións mutuas que se produciron entre o unionismo do Ulster, o nacionalismo irlandés e o rexionalismo galego subliñan as disparidades que deben incorporarse a todo tratamento comparativo. Como interactúa a guerra, librada por Estados imperiais, co rexurdimento lingüístico que se viviu nas periferias provinciais deses imperios? Como interactúa o imperialismo cunha cousa, ou cunhas cousas (sen que, en moitos casos, fique de todo claro o significado ideolóxico dos termos), que se poden denominar ben rexionalismo, ben nacionalismo? Por que o activismo lingüístico resulta unha forza ou axente de mobilización tan importante para os plans autonomistas ou separatistas? E, o máis importante, en que medida gardan relación unhas accións locais e circunscritas a un ámbito social concreto coas súas motivacións e efectos translocais?, ou, noutras palabras, como se produce esa potente implicación mutua?

Trátase de preguntas que son en parte retóricas e en parte heurísticas. Sen afirmar que lles vou dar cumprida resposta a todas elas, nas páxinas seguintes confío en poder extraer algunhas das consecuencias que comportan e presentar un posible modelo que lle aplicar ao considerable reto que claramente se deriva delas: a necesidade de elaborar unha historia debidamente transnacional e comparativa dos movementos nacionais (e rexionais). Nesta tarefa recorrerei aos datos e apreciacións que reuniron, baixo unha perspectiva comparada, os moitos contribuíntes da Encyclopedia of Romantic Nationalism in Europe ${ }^{1}$.

O obstáculo máis grave co que se atopa tal historia transnacional do nacionalismo é a nosa propia estreiteza de miras: a nosa propensión ao nacionalismo metodolóxico. Ao darmos conta dos movementos sociopolíticos segundo se 1 Vid. Leerssen (2018); a versión dixital está dispoñible en liña en https://ernie.uva.nl/. As visualizacións
das redes que se achegan nas páxinas que seguen están tiradas dese sitio web. 
manifestan nun país dado, de maneira predeterminada tendemos a buscar as súas causas e infraestruturas subxacentes no seo dese mesmo país, cunha visión limitada -inveterada e comprensible- que se deriva de tres causas: unha, a de que os arquivos desde os que traballan os historiadores adoitan estar institucionalizados, ordenados e repertoriados a escala nacional e, en efecto, a miúdo se encontran baixo o coidado do Estado; outra, a do problema do idioma, que nos fai gravitar cara ás fontes que somos quen de entender e leva a deixar de lado as escritas en linguas alleas, e a terceira -a menos escusable-, unha arraigada gravitación que se observa nos historiadores cara á explicación dos fenómenos históricos a partir dunhas causas «subxacentes» (é dicir, infraestruturas, sociedade, institucións ou política; noutras palabras, algo propio dun lugar ou dun grupo social). Todos estes elementos tenden a marxinar -erroneamente, ao meu veros factores causais que se comunican a máis longa distancia, desde outros países ou noutras linguas: de xeito sistemático, explicamos o crecemento dunha planta a partir das súas raíces e raramente a partir da súa polinización. Por iso, precísase unha perspectiva transnacional para dar conta da difusión de ideoloxías e movementos a longa distancia, da súa implicación mutua e a súa transferencia, e, en consecuencia, haberá que sacar das sombras das actividades (sociopolíticas) locais os intercambios comunicativos e intelectuais.

Para empezar, os imperios achegan o ambiente en que se producen esas implicacións mutuas transnacionais: as que se dan entre as varias dependencias rexionais e coloniais de Madrid son ben coñecidas e non fai falta volver sobre elas no marco deste artigo. Máis alá, o Imperio Ruso constituíu un elo entre o Báltico e o Cáucaso e, así, o pai da literatura armenia moderna, Khachatur Abovyan, formouse intelectualmente cos seus estudos en Tartu/Dorpat, e o erguemento polaco de 1831 inspirou unha conspiración xeorxiana en 1832. As guerras que se libraron entre estes imperios son o crisol no que se forxou a estatalidade dos movementos nacionais: a Gran Guerra, que comezaron dous imperios multiétnicos (Austria-Hungría e Rusia), acabou co desmembramento nacional de ambos, e a Somme posibilitou o Alzamento de Pascua. 


\section{O TRANSNACIONALISMO DIRECTO: REPERCUSIÓNS}

Os exemplos anteriores xa son indicativos de distintas modalidades do que podemos denominar nacionalismos «de reacción en cadea» ou «de efecto directo», polos cales, nun marco imperial compartido, é posible que un movemento nacional que ten lugar nun punto dado provoque outro noutro sitio. Coido que podemos distinguir varias modalidades nas que toman forma estas interaccións.

1. Unha é a da imitación hostil ${ }^{2}$. Un caso témolo na relación existente entre o nacionalismo irlandés e o unionismo do Ulster: os protestantes desta provincia percibiron os efectos do sistema de goberno local (o obxectivo principal e autonomista do nacionalismo irlandés) e, de resultas disto, iniciaron un movemento contrario de seu, reivindicando a idea de que o Ulster non era irlandés tanto como os nacionalistas irlandeses reivindicaban a de que Irlanda non era británica. Un proceso semellante tivo lugar entre os movementos flamengo e valón en Bélxica e entre os nacionalistas gregos e turcos en Chipre.

2. En segundo lugar, os nacionalismos proliferan mediante a solidariedade activista, cando os activistas de diferentes comunidades unen forzas e estratexias. Este modelo fundaméntase na mobilidade transnacional dalgúns membros importantes deses colectivos, que se viron forzados a esa mobilidade por medio do exilio ou da emigración, entre os que se contan Giuseppe Mazzini, Adam Mickiewicz, Fan Noli etc. Este modelo de «activistas itinerantes» ten particular relevancia para os nacionalismos da diáspora no Novo Mundo e para os activistas anticoloniais de distintas periferias coloniais dos imperios europeos ${ }^{3}$.

\footnotetext{
2 Teño visto que algúns colegas lle atribúen a noción de «imitación hostil» a Ernest Gellner, pero non dei localizado esa expresión nos seus escritos.

3 Cf. Anderson (2005), así como Stutje (2019).
} 
3. En terceiro lugar, uns "padróns organizativos» xenéricos poden resultar unha fonte de inspiración para outros movementos nacionais distintos: desde o formato das sociedades secretas de primeiros do século XIX (Tugendbund, filaretes e filomates, carbonarios, Filiki Etairia, Frăţia) ata a adopción, a finais do século XX, do padrón da «fronte de liberación» (Organización para a Liberación de Palestina, Euskadi Ta Askatasuna, Exército Republicano Irlandés...).

4. En cuarto lugar, pode haber cooperación entre distintas minorías que comparten un sentimento de agravio contra un centro imperial repudiado conxuntamente (como ocorre nas periferias provinciais de España e nas zonas eslavas fronteirizas do Imperio Habsburgo). En efecto, o esfarelamento dos Estados imperiais multiétnicos, sobre todo a raíz da perda de colonias ou sometidos ás tensións da Primeira Guerra Mundial, ofrece unha auténtica cachoeira de nacionalismos de reacción en cadea.

5. Neses imperios que se veñen abaixo pódese observar, no seu centro neurálxico, un quinto subtipo de nacionalismo de reacción en cadea fronte á separación das periferias subalternas (como ocorre na España castelá, en Austria e en Inglaterra). A perda do imperio non é tan só un fenómeno do século XVIII, senón que ten lugar, en vagas sucesivas, ata ben entrado o XX, e en cada unha desas crises xorde no dito centro neurálxico un tipo de «nacionalismo regresivo», un sentido da identidade postimperial nostálxico e virado cara ao rexionalismo (o movemento partidario dunha «pequena Inglaterra»; o movemento reformista español que seguiu a 1898, ou rexeneracionismo; o culto vienés-tirolés que, nos tempos finais do Imperio Habsburgo, se desenvolveu arredor da torta de chocolate vienesa chamada Sacher, os valses de Johan Strauss, o sentimento alpino e a ironía de opereta; o nacionalismo introspectivo neerlandés e dinamarqués posterior a 1839 e 1864), que adoita ter fixación cos monarcas e as tradicións e poida que represente unha supervivencia tardía desa extinta ideoloxía espectral chamada Reichspatriotismus. 
Estas categorías idealtípicas poden, por suposto, superpoñerse ou cruzarse: así, o unionismo do Ulster e o movemento valón poden constituír tanto unha forma de imitación hostil antiirlandesa e antiflamenga como un tipo de nacionalismo regresivo británico e belga, respectivamente; as transferencias vencelladas a «padróns organizativos» ou «activistas itinerantes» adoitan verse en conxunción con outros modelos de transferencia. Porén, paréceme que, entre elas, as cinco categorías en cuestión abranguen a maioría de formas de activismo nacional de «reacción en cadea».

\section{O TRANSNACIONALISMO NON DIRIXIDO: DIFUSIÓN, PROFU- SIÓN, CONDENSACIÓN}

Non obstante o anterior, o aspecto principal que quero sinalar é que estas modalidades de repercusión directa non abarcan a totalidade dos casos de proliferación historicamente documentada do nacionalismo polo continente europeo. En moitas ocasións, o pensamento nacional difúndese -é dicir, esténdese por una zona ampla e de límites esluídos- antes de pasar por un proceso de condensación (e producir efectos) noutro contexto; así, moitas novelas de Walter Scott difundíronse por Europa, traducidas e exportadas, para que unha pequena cifra de autores comezase a aplicar ese xénero literario ao seu propio pasado nacional. Polo xeral, tales procesos de difusión non adoptan unha direccionalidade concreta, non constitúen unha "campaña dirixida de mercadotecnia» que teña un obxectivo definido e os seus efectos non son necesariamente intencionados nin premeditados.

Este feito pode impedir que se perciba con claridade a causalidade que estaba a intervir. Con frecuencia é imposible localizar o extremo de condensación dun proceso de difusión seguindo un rastro linear unívoco de causa e efecto e, en 
consecuencia, a influencia que exerce un caso noutro pode non resultarlle evidente ao historiador. Como na parábola bíblica, hai que sementar -e desbaldirmoitas presas de gran para que algunhas dean froito, pero só de sementes cultivadas vai nacer froito novo. En moitas circunstancias, parecerá que as cousas simplemente están «no aire», formando parte dun Zeitgeist ou condición ambiental dados: coma se o crecemento dos cogomelos fose tan só o resultado do tempo húmido que vén cun cambio de estación, ou coma se a aparición de movementos nacionais se debese meramente ao ascenso da clase media ou a unha etapa de modernidade. No entanto, os cogomelos medran onde medran polo micelio e as esporas que posúen, e a aparición dun movemento nacional sempre se debe á intencionalidade dos intervenientes, que «tiveron a idea», e non a tiraron do aire: as ideas circulaban con profusión, alén de por difusión.

En moitos casos, xa que logo, esta difusión e condensación dependen de que teña lugar unha profusa comunicación de ideas a maior distancia, e moi a miúdo a distancias transnacionais, e moi a miúdo tamén esa comunicación foi tan cultural como política. Polo menos dúas das modalidades antes bosquexadas acharon tamén as súas manifestacións culturais:

- os "padróns organizativos» que se expanden dun movemento nacional a outro relacionado e que non son só modalidades de unión de activistas políticos, senón tamén modos de sociabilidade cultural: sociedades e clubs de lectura, corais, clubs deportivos, e

- os «activistas itinerantes», que nalgúns casos destacados foron artistas e intelectuais, non organizadores políticos: compositores e intérpretes como Franz Liszt e Richard Wagner, ou escritores errantes como Byron, madame de Staël e Washington Irving. 


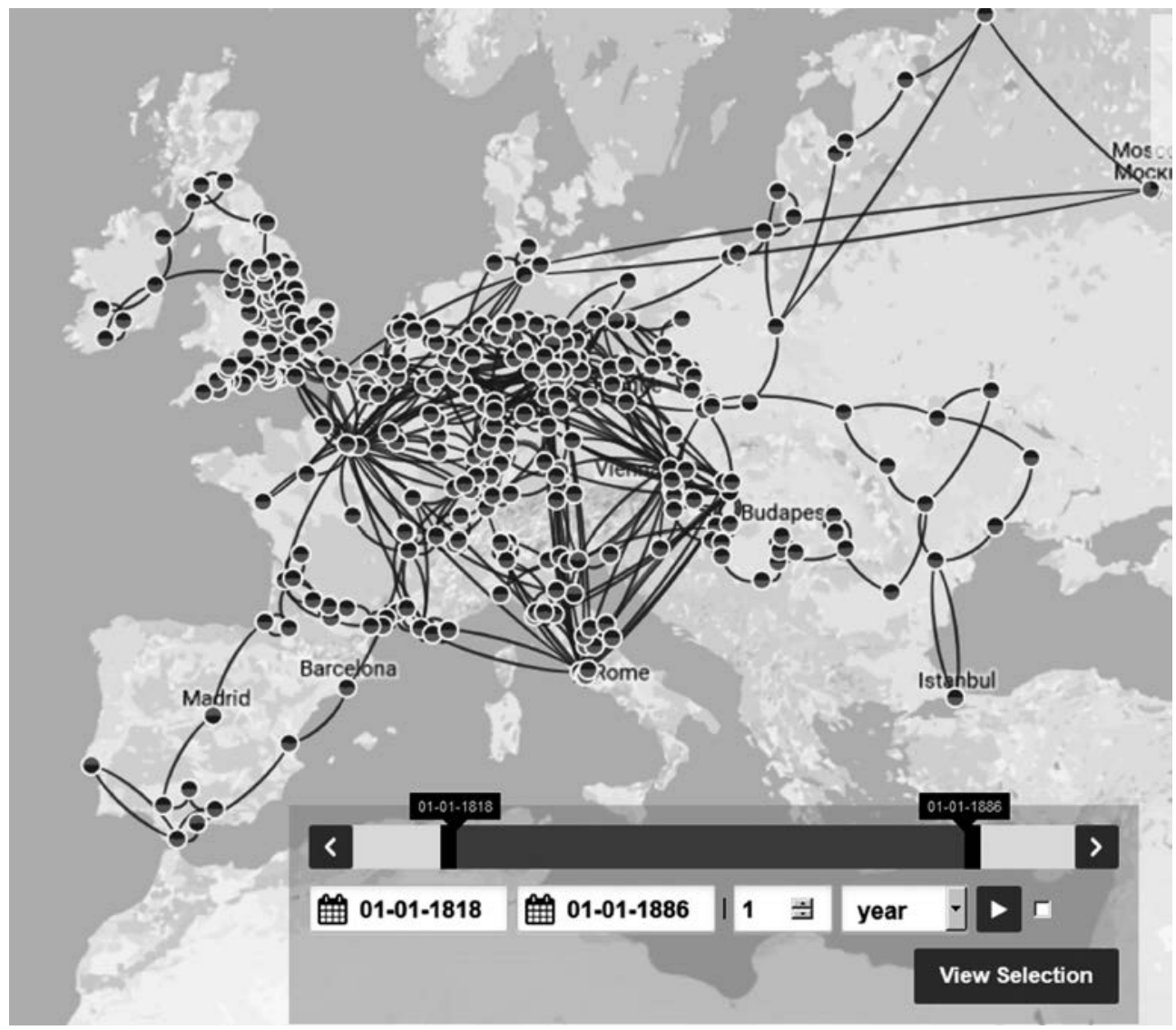

Figura 2.1. Xeiras de Franz Liszt

Para alén do anterior, semella haber algunhas modalidades de transferencia propias do padrón de difusión e condensación cultural, das que relaciono as seguintes:

1. Intercambios institucionais. As academias de arte, os conservatorios, as universidades e os salóns de mostras constitúen puntos de encontro de intelectuais e artistas que saen do seu lugar de orixe, normalmente nunha etapa temperá e formativa da súa carreira profesional. É nestes centros onde as ideas poden pasar do seu ambiente orixinario a outro. Así, Saint Sava, a Academia Principesca de 
Bucarest, precursora da actual universidade desa cidade, foi un importante lugar de reunión dos intelectuais emerxentes que máis adiante asumirían o liderado dos movementos nacionais grego, albanés, romanés etc.; as academias de arte de París, Antwerpen e Düsseldorf aprendéronlles pintura histórica nacional a novas xeracións de artistas procedentes de lugares que ían de Noruega a Polonia e Romanía, por non falar dos círculos de estudo de Roma e das universidades de Viena, Vilnius ou San Petersburgo. A biografía de case todos os artistas e intelectuais que desempeñaron un papel influente no artellamento dos ideais nacionalistas amosa que formaron as súas ideas durante estadías no estranxeiro, e a partir dos contactos que estableceron neses lugares con xente doutros países que tiñan inquedanzas semellantes..

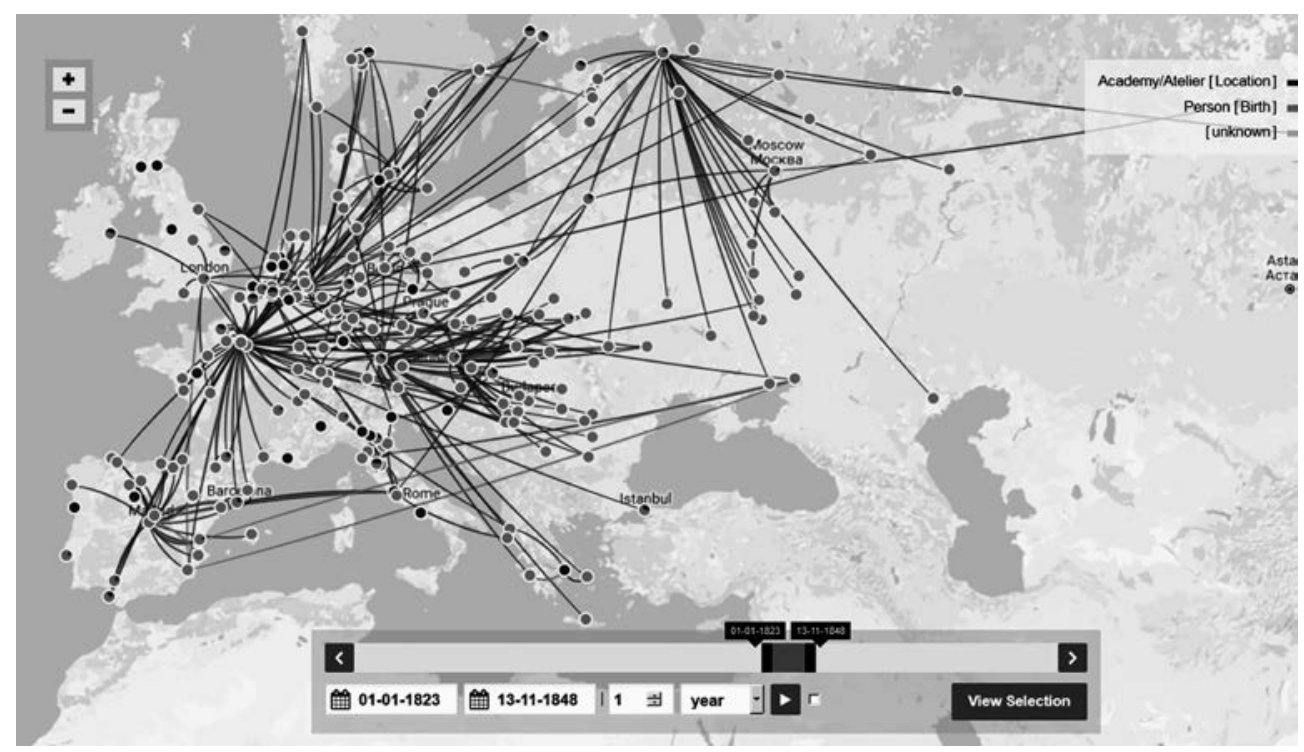

Figura 2.2. Mapa de academias de arte confrontadas co lugar de nacemento dos seus pupilos (1823-1848)

2. Reticulación asociativa. Existiron moitas formas de sociabilidade e camaradaxe que, se ben foran concibidas nun lugar determinado, supuxeron unha fonte de inspiración para iniciativas análogas que xurdiron noutras zonas. Un bo 
exemplo constitúeo a expansión do formato dos «xogos florais» desde Tolosa a Barcelona e de aí a Valencia, San Sebastián e distintas cidades de Galicia e da Provenza, e outro caso atopámolo na difusión dos clubs deportivos e as sociedades corais. Tratábase de iniciativas urbanas que adoitaban atravesar fronteiras políticas ou lingüísticas, e acababan por vincular as cidades de que se tratase nunha rede ou tecido ad hoc, sen as pecharen no ámbito dunha identidade ou territorio compartidos; por exemplo, o formato das corais difundiuse desde a sociabilidade alemá ás nacións bálticas emerxentes. Fose cal for o proceso de construción comunitaria rexionalista ou nacionalista que resultase disto, semella que tivo lugar no hínterland ou rexión circundante de cada cidade en cuestión; só nos países de pequeno tamaño que mostran un baixo grao de urbanización (Gales, Estonia) o hínterland parece máis ou menos coincidente, no plano territorial, cunha nación incipiente. No caso alemán, o efecto de construción nacional que exerceron as corais derivouse da súa concatenación federativa, duns festivais transrexionais compartidos e dun repertorio común ${ }^{4}$.

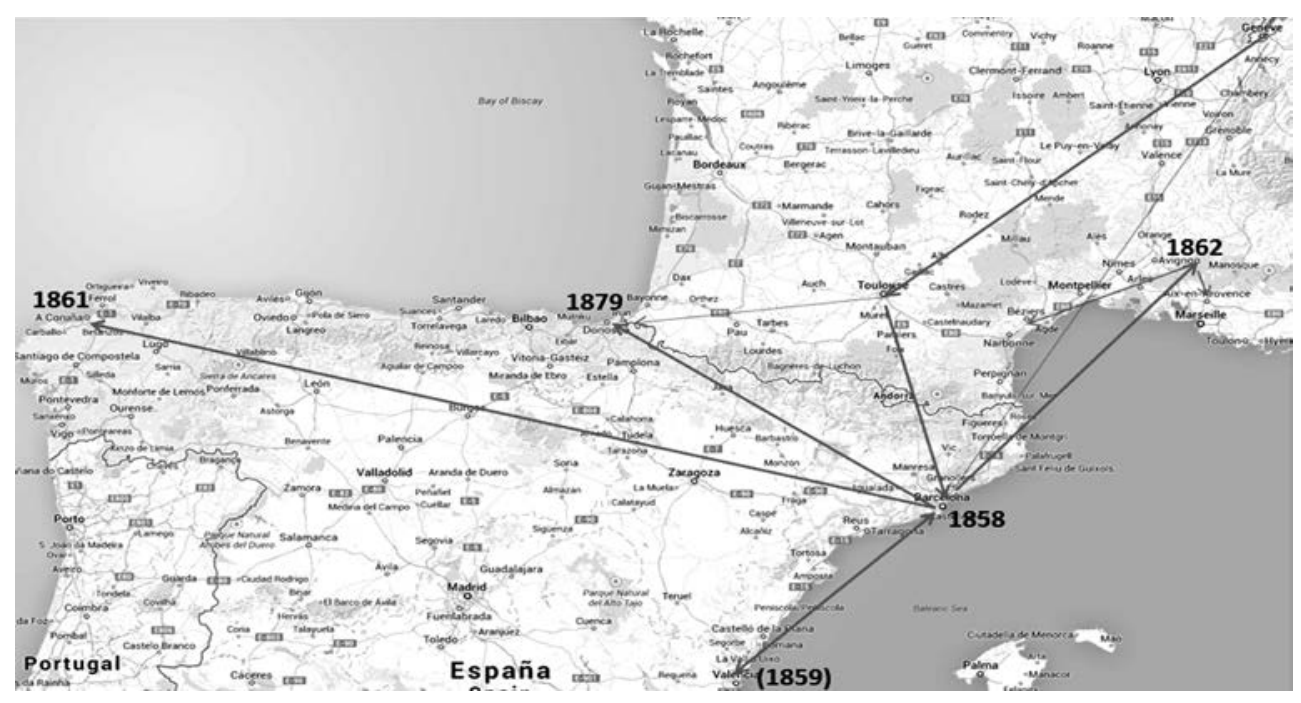

Figura 2.3. Reticulación dos festivais do estilo dos xogos florais

4 Vid. Leerssen (2015), así como Lajosi e Stynen (2015). 
3. O repertorio común dos produtos e actividades culturais non viña delimitado necesariamente pola sociedade ou comunidade cultural individual de que se tratase. A música viaxaba lonxe; foron varios os colectivos de diversas partes de Europa que tiveron a impresión de que $A$ Marsellesa, o coro $V a$, pensiero do Nabucco de Verdi e a aria Amour sacré de la patrie de A muda de Portici de Auger cadraban coas súas tribulacións e aspiracións. Os poemas de lord Byron, as novelas de Walter Scott e o Don Carlos e o Guillerme Tell de Friedrich Schiller tiveron tanta influencia traducidos -e entre lectores versados no plurilingüismocomo na súa propia área lingüística de orixe. As Edda e Beowulf constituíron unha fonte de inspiración para o público alemán, o inglés e o escandinavo por igual, e Ján Kollár e Vuk Karadži resoaron por todo o mundo eslavo.

4. A intensa comunicación de ideas que se produciu entre os intelectuais nacionalistas románticos serviu para divulgar, dun modo viralmente contaxioso, as ideas xeradas polas novas modalidades de produción de coñecemento nun marco nacional, sobre todo entre filólogos e historiadores. Aínda que, cada vez máis, vían a súa tarefa desde esa perspectiva nacional (e, neste sentido, Jacob Grimm era un fervente patriota alemán na mesma medida en que Michelet o era francés), mantiñan correspondencia uns con outros, facían recensións das obras dos demais e alistábanse mutuamente nas súas respectivas sociedades eruditas nacionais, creando unha rede de notable densidade. Tomando como base unha mostra de arredor de 40000 cartas entre figuras «nodais» de capital importancia, como foron, entre outros, Jacob Grimm e Walter Scott, podemos afirmar, sen temor a equivocármonos, que non houbo dous intelectuais románticos, desde Reiquiavik a Odessa, entre os que existisen máis de dous «graos de separación». Así, abondan dous correspondentes intermedios para vencellar a Théodore Hersart de La Villamarqué, coleccionista de baladas bretón, con Anders Sjögren, presidente finés da Academia Imperial das Ciencias rusa, sita en San Petersburgo. Ao mesmo tempo, con todo, estas redes presentan unha distribución concreta que indica as simpatías e antipatías dos protagonistas do ámbito cultural: a 

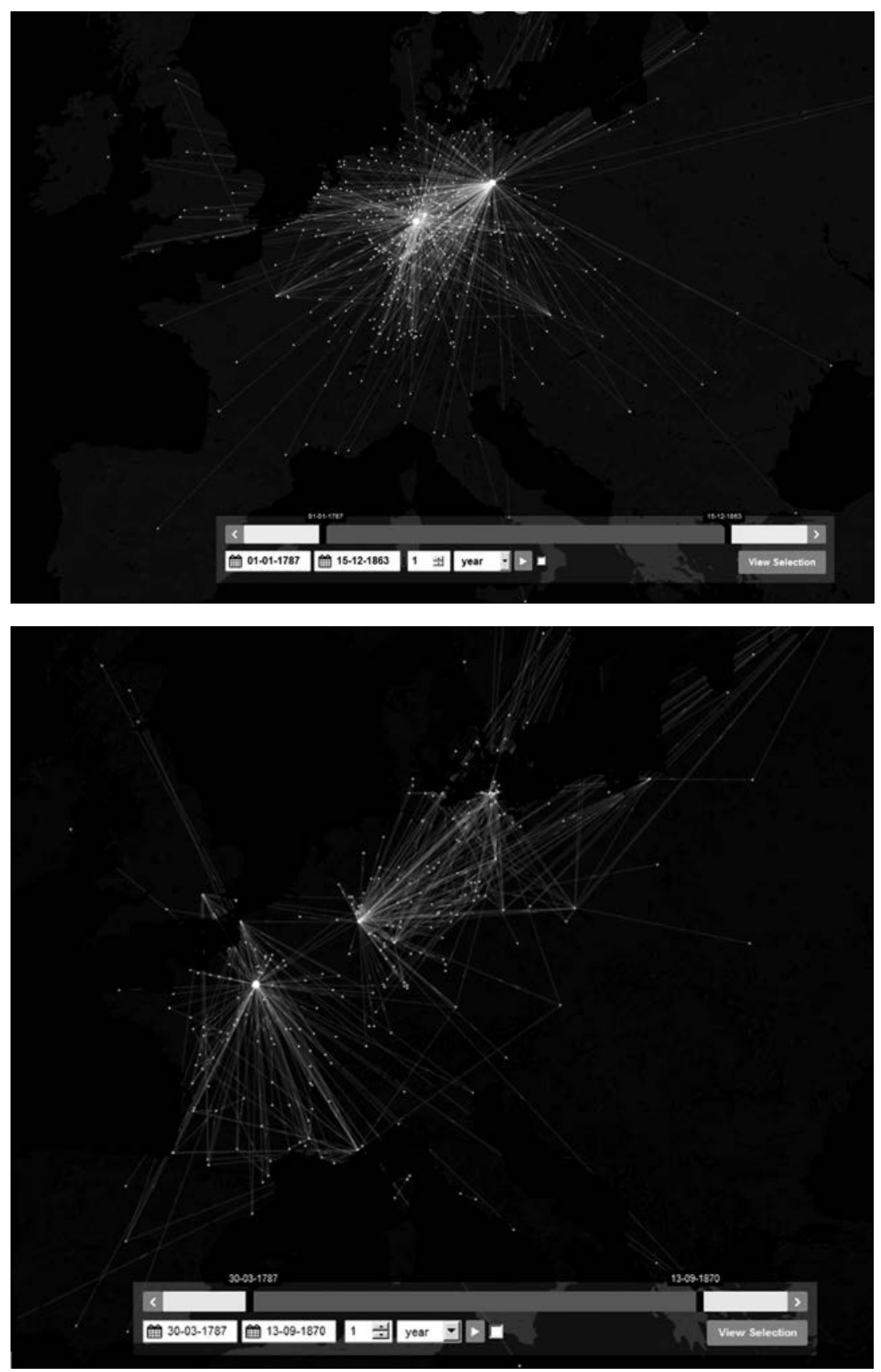

Figs. 2.4 e 2.5. Redes de correspondencia de Jacob Grimm e, xustapostos, E. M. Arndt e Prosper Mérimée 
fenda que dividía a rede non francesa de Ernst Moritz Arndt e a rede non alemá de Prosper Mérimée -ambos os dous case contemporáneos, situados nunha posición cultural máis ou menos equiparable e cunha cantidade máis ou menos igual de cartas repertoriadas, con cerca de 4000 cada un- ilustra, dun xeito rechamante, o crecente distanciamento franco-alemán e, trasladada a un mapa espacial, esta «zona morta» comunicativa constitúe un desacougante anticipo das primeiras liñas da Gran Guerra.

\section{A ACEPTACIÓN DA COMPLEXIDADE}

O estudo destes intercambios implica o necesario rastrexo de múltiplas pistas en papel e probas documentais difusas en moitas direccións, case como trazando a estrutura do micelio que vencella os distintos cogomelos dun bosque, ou a difusión das súas innumerables esporas cos ventos cambiantes. Os procesos en cuestión non son senón complexos e calquera relato linear do estilo «desde unha causa aquí ata un efecto alí» vai poñer no primeiro plano unha febra dada e deixar desatendidas moitas outras na embrolla da madeixa. As dinámicas dos movementos nacionais, unha vez liberados da simplificación artificial que impón unha estreiteza de miras mononacional e monodisciplinaria, constitúen a definición mesma de «non-linearidade», e deben trazarse e visualizarse co medio axeitado para esa súa condición: o estudo dos sistemas complexos, que comporta instrumentos de redución da complexidade tales que o levantamento de matrices multidimensionais e mais a análise de redes. A Encyclopedia of Romantic Nationalism in Europe concibiuse como un "estudo de viabilidade» de tal achegamento, co emprego dunha matriz tridimensional que dá lugar a distintos eidos e medios de produción cultural (filoloxía, artes visuais, folclore, música etc.) contrastados cunhas comunidades culturais autodefinidas (desde os albaneses aos galeses) e, nunha terceira dimensión, coa cronoloxía dos acontecementos culturais observados de 1780 a 1920. 
É este último aspecto, a insistencia na diacronía e na databilidade das prácticas culturais - pois, como expresou Hugo von Hoffmannsthal, «Jedes Wort ist doch auch ein Ereignis»-, o que distingue este achegamento das formas sociocientíficas de trazado de matrices e análise de redes. A diacronicidade é tanto máis importante canto que os movementos rexionalistas e nacionalistas de Europa, se ben adoitaban seguir unha secuencialidade parecida no seu desenvolvemento, basicamente dentro do «moi longo século XIX» (de acordo, por exemplo, co modelo de fases de Miroslav Hroch, ao que volverei máis adiante), comezaron uns antes que outros, e uns pasaron por determinadas etapas máis rápido que outros; porén, todos compartiron as mesmas datas constitutivas críticas, como 1813-1815, 1848 ou a guerra de Crimea.

Con estas tres dimensións (campos, comunidades e cronoloxía), o sistema europeo pode trazarse máis ou menos coma se fose un cubo de Rubik e, malia que as varias voltas e reviravoltas dun cubo tan articulado chegan a resultar desconcertantes, polo complicadas -igual que é, e era, a vida real-, o sistema en si reduce esas complicacións a complexidade: algo que non é nin linear nin caótico, unha cifra ilimitada de permutacións que se encadran nunha cifra limitada de parámetros descritivos.

$\mathrm{Na}$ liña da teoría do actor-rede de Bruno Latour ${ }^{5}$, nesa visión dos movementos nacionais vanse analizar non só as personalidades humanas intervenientes -ou ese primum movens metafísico do século XX, «a sociedade»-, senón tamén produtos culturais como libros, composicións musicais, estatuas e asociacións, pois tamén teñen poder conectivo e axencia causal. Ao mesmo tempo, a perspectiva non é sociolóxica, senón histórico-cultural, hermenéutica e non cibernética, no sentido de que a importancia de cada actor vén determinada non pola súa mera presenza, senón pola importancia que lle atribúen os demais, tendo en conta que os actores humanos constitúen elos indispensables na arbitraxe da

5 Vid. Latour (2005). 


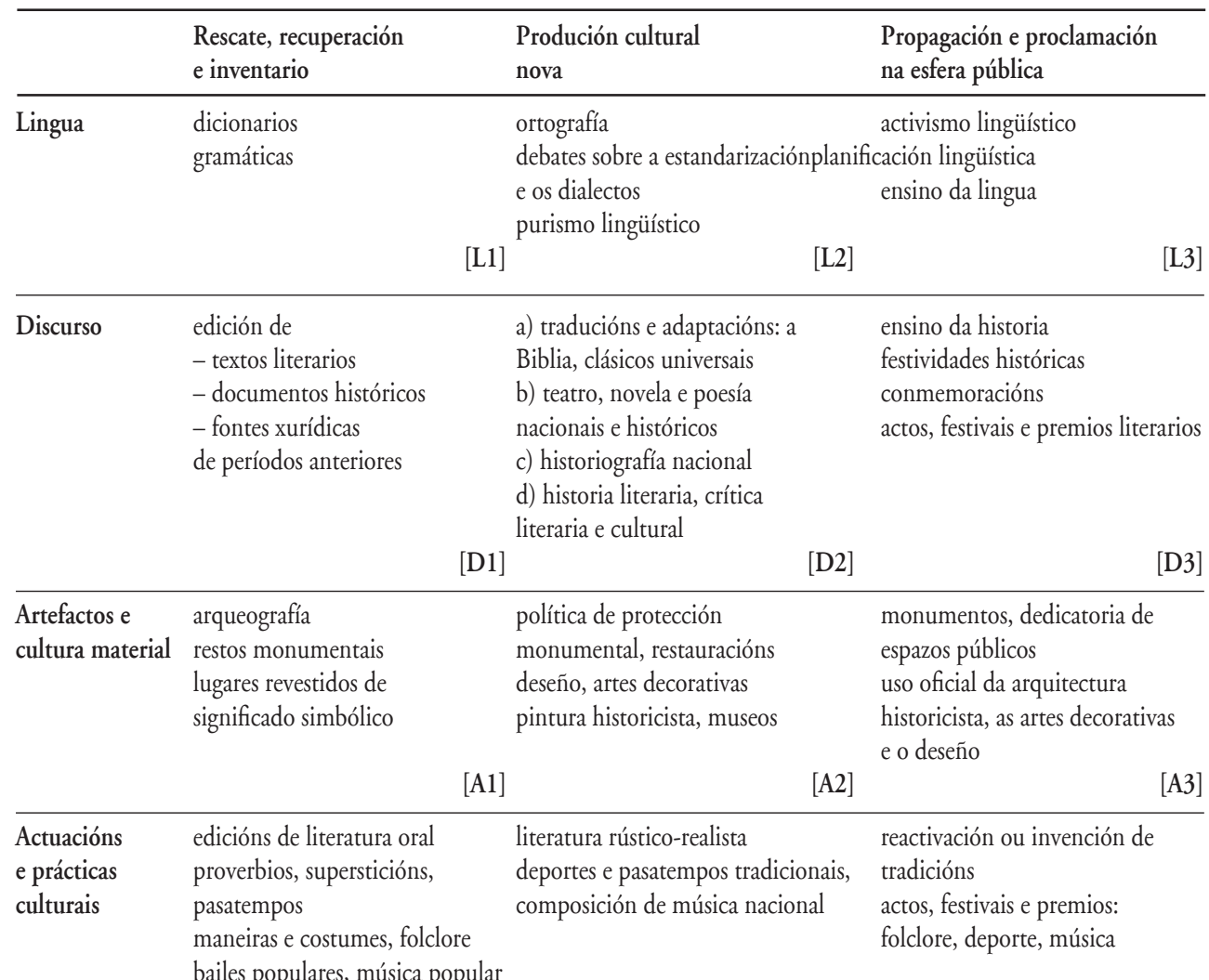

Ambiente social

a) asociacións, academias urbanas, sociedades de lectura

b) publicacións periódicas, operacións de edición

Infraestrutura institucional

a) academias estatais, universidades, cátedras

b) librarías, arquivos

c) museos, Administracións públicas

Fig. 2.6

dita relevancia. Xa que logo, a ausencia ou presenza da diferenza lingüística non é, como tal, decisiva en por si: hai idiomas moi «distintos» entre si, como as linguas sami, que non se instrumentalizaron na toma de conciencia nacional máis que dun xeito tardío e dubitativo, mentres que as diferenzas, relativamente 
secundarias, que existen entre o ucraíno e o ruso, ou entre o búlgaro e o macedonio, se tomaron certamente moi en serio. Pola contra, o que importa é a relevancia que a xente daquel tempo lle atribuía á diferenza lingüística, e de aí que a noción de «cultura», tal e como se usa aquí, se refira sempre a algo que se experimenta e sobre o que se reflexiona (a experiencia da cultura, a reflexión cultural) e se incorpore á reiterativa noción do «cultivo da cultura». Non é a cultura, senón o seu cultivo e valoración, o que marca a transición do comportamento antropolóxico á ideoloxía política, e tamén o que nos permite facer un trazado da «cultura» (en canto conxunto de prácticas e campos) comparándoa con diversas modalidades de cultivo e indicando graos de intensidade nese proceso, o que nos dá a matriz que vai seguir ${ }^{6}$ :

Non pode afirmarse que a metodoloxía da que aquí se fixo un breve esbozo sexa a única maneira de abordar un estudo debidamente transnacional e comparativo dos movementos nacionais e rexionais de Europa. Porén, con ela si se tenta encarar o reto fundamental ao que se enfronta todo achegamento propiamente transnacional ao nacionalismo e ao rexionalismo: a necesidade de incorporar a axencia da comunicación transfronteiriza e o feito de que, nesta, a difusión cultural non sexa menos importante que as repercusións políticas directas.

\section{DE VOLTA EN DUBLÍN E NA CORUÑA: NACIONALISMO, REXIO- NALISMO E MULTIPLICIDADE DE ESCALAS}

En todos estes factores culturais e comunicativos enténdese Europa, ao estilo de Latour, como rede de intercambios, visión que é contraria ao arraigado hábito de a entender como crebacabezas de Estados-nación discretos e pechados, ou como sistema gravitacional aniñado de centros e periferias, ateigado de subcentros e

6 Cf. Leerssen (2006). 
subperiferias. Unha perspectiva en rede comunicativa libera as Irmandades da Fala, malia a súa posición (duplamente) periférica en España e Europa, da súa percibida marxinalidade, ademais de situar a Galicia como participante na renacenza rexionalista das comunidades subalternas de linguas ibérico-romances e, igualmente, como pedra de toque entre Irlanda e Cuba ou a Arxentina (onde a influencia que exerceron os colectivos galegos ao longo destes anos é relativamente comparable ás actividades que desempeñaron as diásporas irlandesa, polaca, eslovaca e croata nos Estados Unidos).

Desde o principio, saltan á vista os paralelos e as diverxencias existentes entre o caso galego e o irlandés. En ambos, a mobilización sociopolítica se leva a cabo baixo a invocación do idioma nativo. Así, o obxectivo principal e ostensible das Irmandades dos Amigos da Fala, constituídas na Coruña un mes despois do Alzamento de Pascua, foi o de preservación do idioma e rexurdimento lingüístico, de nos atermos ao seu nome. (E, mesmo se esa denominación fose un código «encuberto» e eufemístico para reivindicar un maior autonomismo político, ao estilo das asociacións Tugendbund ou Filiki Eteria, a escolla do eufemismo non deixa de resultar significativa.) Dun xeito semellante, en Dublín a metade dos asinantes da Declaración de Independencia de 1916 chegaran ao separatismo armado por medio dunha asociación promotora do rexurdimento lingüístico que fora fundada en 1893: a Liga Gaélica. Este colectivo, que dedicaba os seus esforzos a un programa de renacenza cultural nativista que recibía o nome de «desanglización», organizara concursos de música e baile, obras de teatro amador, excursións turísticas á Irlanda occidental, de fala gaélica, e, por riba de todo, aulas de lingua nas que o pobo irlandés podía reconectar cun idioma, o seu, que ía desaparecendo con rapidez. No que constituíu unha confirmación típica do modelo de fases de Miroslav Hroch ${ }^{7}$, esas actividades de toma de conciencia cultural logo deron lugar a un choque de demandas sociais, principalmente

7 Dos moitos escritos, mencionarei a Hroch (2005). 
verbo do ensino do gaélico e o seu emprego nos enderezos postais e nos letreiros comerciais. Entre 1905 e 1910 a organización radicalizouse, ata o punto de converxer con partidos políticos separatistas como o Sinn Féin e ser obxecto de infiltración por parte de activistas terroristas da Irmandade Republicana Irlandesa, que contaba cunha rama americana. Neste proceso de radicalización, o obxectivo do rexurdimento lingüístico converteuse en mera política simbólica e o núcleo do plan de acción nacionalista virou da renacenza cultural ao separatismo sociopolítico ${ }^{8}$.

A conexión Dublín-A Coruña foi unha transferencia directa por reacción en cadea ou un caso de difusión cultural? O meu coñecemento das fontes (limitado, hai que admitir) lévame a sospeitar o segundo. Estes dous movementos non tiñan metas comúns, sentimentos compartidos de aldraxe nin intermediarios directos, e entre as respectivas linguas que se enarboraban como bandeiras de campaña en Dublín e na Coruña non había nin familiaridade nin rivalidade. En cambio, existe unha historia ben documentada de intelectuais galegos que internalizaron ese inspirador paralelo que se establecía coas demais periferias atlánticas e deron en empregar a denominación común de «celtas» para invocaren un ambiente compartido de chuvia e gaitas. $\mathrm{O}$ celtismo galego remóntase nada menos que a mediados do século XIX, cando unha serie de historiadores, como Benito Vicetto e Manuel Murguía, escribiron sobre as primeiras épocas da historia do país á luz dos mitos migratorios gaélicos, e chegaron mesmo a apelar á figura mitolóxica gaélico-irlandesa de Breogán como devanceiro nacional. Máis aínda, en 1935 Antón Villar Ponte, pai fundador das Irmandades da Fala, traduciu para o galego, xunto con Plácido R. Castro, as obras teatrais de W. B. Yeats Cathleen Ni Houlihan e The Land of Heart's Desire, ambas de sentimento nacional irlandés?.

\footnotetext{
8 En Leerssen (2016a) poden consultarse máis pormenores e fontes.

9 Antón Villar Ponte xa traducira Cathleen Ni Houlihan para o galego en 1921 (Nós, 8, 5 de decembro de 1921). Vid. tamén http://www.fundacionplacidocastro.com/reflexions-arredor/irene-romero-iturralde/ historia-dunha-traducion-placido-castro-anton-villar-ponte-e-dous-folc-dramas-de-w-b-yeats, así como Leerssen (2016b), por cuxa parte galega estou en débeda con Fernando Pereira e o seu traballo.
} 
Entre a mitografía e a historia do decenio de 1880 e as traducións de Villar Ponte, a documentación apunta a que os nacionalistas galegos se fixaron en Irlanda, efectivamente, como punto cultural de referencia. Os contactos entre ambos os dous países foron de natureza cultural, máis que de activismo social, e, como adoita ocorrer coas conexións culturais, tamén indirectos. Neste sentido, son dúas as pedras de toque intermedias que vencellan os intelectuais galegos coa mitoloxía irlandesa: unha é o filólogo celta Henri d’Arbois de Jubainville, catedrático do Collège de France, cuxos estudos mitolóxicos consultou Murguía, e a outra é Joaquín de Villanueva (1757-1837), crego liberal exiliado e exdeputado das Cortes de Cádiz que se refuxiara en Dublín, onde empezara a interesarse pola pescuda anticuaria gaélico-irlandesa (aos escritos que lle dedicou ao tema gaélico recorreu Vicetto con frecuencia).

Non obstante, tanto a Liga Gaélica como as Irmandades da Fala presentan unha instrumentalización da cultura para uns fins de activismo sociopolítico. Posúen unha inspiración cultural común difusa e paneuropea, mais unha esfera de acción estritamente local, dirixida ao seu propio país. Esa é, en si mesma, unha conclusión para termos presente: o cultivo da cultura adoita comunicarse a escala transnacional, mentres que a acción política é principalmente intranacional.

Porén, hai outra inferencia que querería derivar da comparación entre a Liga e as Irmandades, que é a de que o activismo lingüístico en Irlanda nunca foi rexionalista, mentres que en Galicia tivo dúbidas en chamarse nacionalista. A diferenza do que ocorreu co desenvolvemento do activismo lingüístico gaélico, o cultivo do idioma galego non conduciu a ningunha rebelión separatista armada nas rúas da Coruña ou de Santiago de Compostela, nin a proclamacións temporais dunha república galega independente.

Onde acaba o rexionalismo e comeza o nacionalismo? A pregunta resulta incómoda e ten sido obxecto de moito debate, e enceréllaa o feito de que a palabra posúa connotacións bastante distintas nas distintas linguas e nas diverxentes autopercepcións ideolóxicas dos varios movementos que se chamaban a si mesmos «rexionalistas». Un punto de partida que é de sentido común podería estar 
en que o rexionalismo comporta o cultivo de diferenzas culturais que non se consideran tan esenciais como para excluíren a participación dunha comunidade cultural no Estado-nación; noutras palabras, o rexionalismo é o autoposicionamento dun «grupo étnico autodiferenciado» -por citar a definición de nación de Walker Connor ${ }^{10}$, que non implica separatismo. Se o rexionalismo leva consigo algunha reivindicación de «autonomía», esa autonomía concíbese como autogoberno subsidiario dentro do Estado e suxeito á soberanía deste.

Tal distinción ten sona de resultar problemática. Para empezar, non é estable no tempo: o que nun momento dado pode ser rexionalismo evoluciona cara ao separatismo máis adiante e, á inversa, é posible que o que nunha época concreta pasa por diferenciación nacional sufra unha erosión que, co tempo, o deixe en mera variación rexional. Máis aínda: dado que, na vida cultural, a existencia que ten o pasado tras a súa morte pode superpoñerse á aparición do futuro (a Gleichzeitigkeit des Ungleichzeitigen de Reinhart Koselleck), cabe a posibilidade de que vexamos ambas as dúas tendencias representadas nunha única sociedade, unha a carón da outra, nun momento dado. $\mathrm{O}$ espectro político normalmente abrangue diversas gradacións de rexionalismo de baixa intensidade á beira dun nacionalismo radical; a este respecto, o caso de Valencia constitúe un exemplo ilustrativo, coa complicación engadida de que o Outro contra o que se posiciona o rexionalismo valenciano pode ser, dun xeito fluído, quer Madrid ou Barcelona, quer ambos.

Estas anomalías - porque iso é o que deben de parecer nun marco analítico no que o rexionalismo e o nacionalismo constitúen categorías independentes, unha máis ou menos representada, en Galicia, polo Consello da Cultura Galega e outra, en Irlanda, polo IRA- fican reducidas a un formato máis manexable se as consideramos desde unha óptica transnacional. En efecto, esta comporta máis que unha serie acumulativa de casos nacionais discretos que pasan a formar parte

\footnotetext{
${ }^{10}$ Connor (1994).
} 
dunha «Liga de Campións» multinacional; significa, ademais, que a índole unitaria discreta do plano nacional se pon en dúbida e se percibe nas súas diferenciacións internas tanto como nas súas conexións externas. As implicacións mutuas transnacionais e a polinización cruzada demostran que as nacións non son, á maneira de callaos, lisos, duros e ben diferenciados; e, do mesmo xeito que por fóra non son lisos e impenetrables, por dentro non son homoxéneos, cristalinos e indiferenciados. Adoitan producirse conexións internacionais entre as cidades provinciais e as súas respectivas rexións, como amosa a reticulación dos xogos florais.

A noción de que as implicacións mutuas transculturais se dan entre cidades e entre rexións, e tamén entre nacións, todo ao mesmo tempo, coñécese agora como «multiescalaridade», o que significa que o autoposicionamento cultural e o «cultivo da cultura» poden ter lugar no plano urbano ou municipal, no rexional ou no nacional, e a miúdo estes interactúan entre si. Desta maneira, Praga pode ser bohemia ou checa, habsbúrxica, paneslava ou a contorna urbana de (segundo cadre) Franz Kafka, o golem, Bed ich Smetana ou Jaroslav Hašek. Canto da Renaixença catalá foi unha cuestión non de rexionalismo, senón de cultura urbana barcelonesa? Canto do nacionalismo cultural holandés é unha elevación da cultura urbana de Amsterdam a un nivel de importancia nacional? En calquera momento, o cultivo da cultura e as autoafirmacións poden ir pasando do municipalismo ao rexionalismo e de aí ao nacionalismo... e logo facer o percorrido inverso, como demostra a historia de cidades como Florencia, Múnic e Edimburgo.

Noutras palabras, que un movemento nacional chegue a unha fase $\mathrm{C}$ hrochiana de axitación das masas depende tanto da intensificación das súas demandas e do seu antagonismo antiestatal como da escala da súa zona de captación, ambas as cales están supeditadas ás accións e circunstancias que se dean nun momento dado. 


\section{CONCLUSIÓNS: DIRECCIONALIDADE E DIACRONÍA}

Entón, que é o que bosquexei aquí, unha cerellada amorfa? Ata certo punto, si: e o encerellamento é a mensaxe. Os movementos nacionais que teñen lugar en Europa son transnacionais e moi fluídos, na súa autodefinición cultural, o seu autoposicionamento e as súas implicacións mutuas de natureza transnacional, o cal, en si mesmo, debería constituír unha saudable chamada de atención para calquera que desexe atrapar esta enguedellada complexidade nunha pulcra tipoloxía determinista; unha chamada de atención contra un presentismo irreflexivo ou un finalismo anacrónico que retroproxecte o panorama etnolingüístico e ideolóxico-nacional contemporáneo de Europa no pasado, valéndose inxenuamente do mundo que coñecemos como mapa significativo do que o mundo era antes; contra un nacionalismo metodolóxico que, de maneira maquinal, faga uso do Estado como parámetro fixo mediante o cal se poden sistematizar estas dinámicas. Talvez o Estado nos ordenase os arquivos e centros de investigación, estruturando as condicións nas que nos achegamos ao pasado, pero a organización dos nosos arquivos non é un reflexo fiable dos acontecementos históricos en si mesmos.

Mesmo así, concluír que o pasado foi unha maraña encerellada transnacional non ten por obxecto resolver a cuestión. Unha vez que se recoñeceu e, en certa medida, se esquematizou esa complexidade, podemos dicir algo verbo de posibles padróns, trazos estruturais ou secuencias de desenvolvemento nela?

Historicamente, vanse visibilizando unhas poucas liñas evolutivas xerais que xorden das complexas análises de datos e esquematizacións que presenta a Encyclopedia of Romantic Nationalism in Europe, entre as que vou perfilar algunhas tendencias que se observan a grande escala en diversos campos e medios culturais e en distintas comunidades nacionais de Europa. 
- Unha viraxe «do pasado ao campesiñado»: nas súas etapas iniciais, o cultivo nacional da cultura adopta un cariz moi historicista, gravitando sobre todo cara a unha Idade Media cabaleiresca; máis adiante, vólvese a mirada ao campesiñado contemporáneo e á xente que mora no rural, que son considerados os auténticos depositarios da identidade da nación. Isto ten o seu reflexo nas artes visuais, desde a pintura de xénero monumental á rústica e ao ascenso das artes decorativas (adoito de inspiración vernácula); na literatura e na ópera, vemos a viraxe desde a temática historicista aos idilios rústicos e os dramas campesiños; na arquitectura, hai unha preferencia variable, que se move dos neoestilos historicistas ou o eclecticismo aos elementos vernáculos.

- Na produción de coñecemento (historia, filoloxía, folclore), apreciamos un xiro que nos leva do interese amador á profesionalización e o factualismo, vencellados aos avances institucionais que teñen lugar arredor das universidades e ao ascenso do positivismo. Ao mesmo tempo, a tradición romántica amadora das primeiras xeracións conserva a súa influencia na cultura popular e na produción cultural.

- A aparición, a finais de século, do nacionalismo de vangarda, do que a miúdo foron portadores os progresistas utópicos que se inspiraban no movemento Arts and Crafts (Artes e Oficios), e que tiña por obxecto reivindicar a nación como parte integrante, de pleno dereito, dunha modernidade europea progresista. Esta onda adoita estar enfrontada coa persistencia dun nacionalismo anterior, nostálxico e nativista.

- Á vez, endurecemento do discurso sobre a etnicidade, segundo o cal as nocións de sangue e ascendencia se empregan cada vez menos como metáforas da herdanza transxeracional da cultura, e máis como invocacións literais e físicas dun racismo biolóxico.

- Unha diseminación comunicativa que, no transcorrer do século, ascende do plano local (solitario, privado ou de sociabilidade) ao colectivo ou público. Nos medios literarios, comporta unha viraxe desde a poesía á 
novela e as publicacións periódicas, a ópera e o teatro; na cultura asociacionista, un xiro desde os entretementos privados e os salóns e as redes da familia extensa ata as asociacións urbanas, os museos, os teatros e óperas e a sociabilidade de clase media, con actividades translocais.

Estas correntes de grande escala permiten abordar algunhas interrogantes máis concretas da pescuda comparatista. Por que o renacer da vestimenta tradicional, e a súa adopción polas clases medias urbanas, tivo máis importancia ou éxito nuns países (o Tirol, Escocia, Letonia, Noruega) que noutros? Cales foron os efectos mobilizadores dos clubs deportivos (Turnverein, Sokol), ou das actividades de tipo excursionista (Cataluña, terras eslovacas), ou do teatro amador (Noruega, Irlanda, Islandia), nos distintos países? Como damos conta das diferenzas existentes entre a cultura musical nacional de Gales (onde tivo relevancia o canto coral) e a de Irlanda (onde foron máis importantes o canto informal en contextos de sociabilidade, a música instrumental e o baile)? Que función desempeñaron os cancioneiros clásicos no repertorio nacional de Alemaña, Dinamarca e outros países? Que escolas, estilos e liñas de difusión seguiu a expansión dos estilos nacionais arquitectónicos por Europa, e por medio de que redes de ensino profesional?

O máis importante, por suposto, dado tamén o tema que nos ocupa, é que papel desempeñou a mobilización lingüística nos diversos países. En case todos os movementos nacionais observamos unha tensión entre os cultivos historicistas da lingua e os demóticos: entre quen prefiren unha lingua formal continuadora da prestixiosa tradición literaria dun pasado glorioso e os que optan por un idioma menos formal que se dirixa ao conxunto da comunidade popular de falantes actuais. Polo xeral, a tendencia europea amosa certo ascendente das formas populares modernas a medida que transcorre o século. Ata que punto foi o activismo lingüístico unha cuestión importante por dereito propio ou, pola contra, unha plataforma de lanzamento doutros obxectivos e problemáticas nacionalistas? Como influíu a intolerancia estatal (posta de manifesto, en distintos graos, 
en diversos países europeos, indo da indiferenza á represión activa) na mobilización das linguas minoritarias ${ }^{11}$ ?

En varios momentos desta contribución, referinme aos procesos de intensificación, radicalización e instrumentalización, a miúdo no contexto do modelo de fases de Miroslav Hroch. Gustaríame que se entendese que estes vectores non se poden trazar sen ambigüidades no tempo, nin se lles poden asignar unhas datacións concretas nuns períodos determinados: hai movementos que son máis temperáns que outros, e non se pode determinar con uniformidade cando ou despois de canto tempo se fai a transición desta fase a estoutra nun caso dado. Para alén diso, o cultivo da cultura actúa en calquera das fases hrochianas, que coido que non deberían verse como unidades sucesivas e ben diferenciadas, igual que vagóns dun tren, senón, pola contra, como as precipitacións e a velocidade do vento segundo cobran intensidade nun sistema meteorolóxico. Se, dentro dese «cultivo da cultura», se fai o trazado dun proceso de intensificación que vai do rescate á produtividade e de aí á instrumentalización propagandística, isto tamén debería entenderse como as gradacións dun proceso fluído que se intensifica, e non como unha sucesión trifásica claramente demarcada.

Poden ir e vir vagas dalgún tipo de afirmación cultural máis intensa ao tempo que continúa con toda a súa forza algunha forma máis anódina de preocupación cultural, pero, aínda que o proceso de intensificación non resulta irreversible, a súa nacente direccionalidade é invariante: os movementos emerxentes tenden a

\footnotetext{
${ }^{11}$ Neste contexto, vou pasar por riba da cuestión, intrigante pero moi complexa, de en que medida o rexionalismo garda relación co nacionalismo igual que un «dialecto» garda relación cunha lingua. No plano ideolóxico faise, abofé, esa correlación: moitos movementos nacionais do século XIX trataron de demostrar, por todos os medios, que se comunicaban nunha linguaxe que podía considerarse un «idioma», non un mero patois; porén, á hora de articular esa distinción fluída e moi debatible, pero categórica, tiveron peso un gran número de consideracións vagas e heteroxéneas: o lugar filoxenético ou cladístico que ocupan as maneiras de expresión locais fronte ao idioma oficial do Estado (onde o esloveno xoga a baza do dual como trazo distintivo), a historia da alfabetización ou da literatura de expresión local (onde o ucraíno e o macedonio amosan unha ascendencia de seu correspondente ao antigo eslavo eclesiástico e, no caso do catalán e o occitano, ao latín) e a súa utilización na esfera pública moderna (medios impresos, produción cultural).
} 


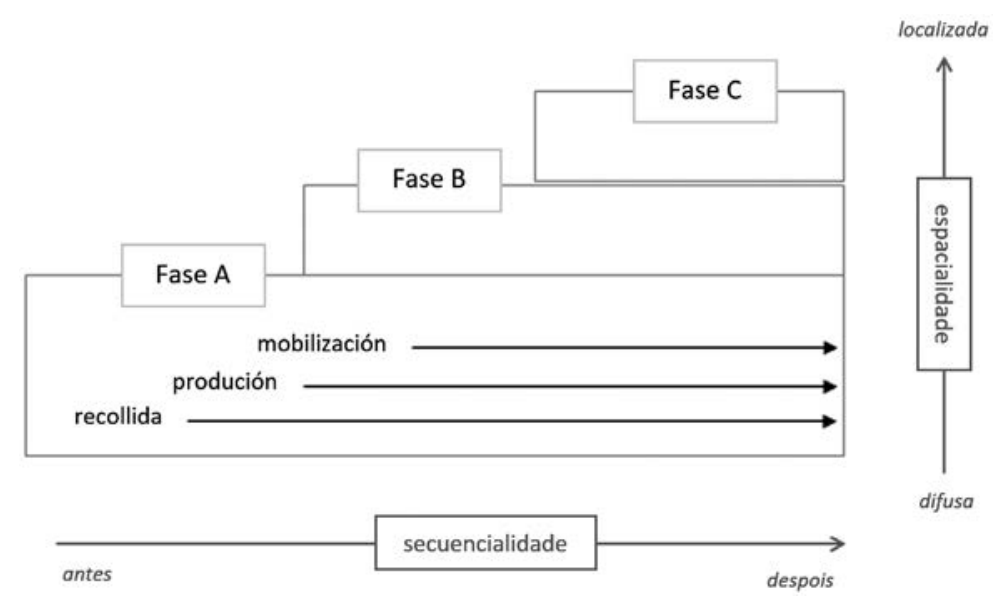

Fig. 2.7

superpoñerlle á fase inicial, insulsamente cultural, outra máis decididamente política. Nunca xorden por intensificación duns comezos políticos insulsos mediante unha decidida radicalización cultural. Eu manteño que esa lóxica direccional en estadios ten un carácter fundamental, ubicuo e moi significativo na Europa do XIX, e tamén quere dicir que as transferencias que se fan por medio da cultura revisten, en comparación, máis importancia na fase A culturalista dos movementos nacionais, ou certamente no rexionalismo, e que ese nacionalismo de reacción en cadea e a difusión dos seus efectos se tornan máis relevantes nas etapas de maior activismo (fases $\mathrm{B}$ e C). $\mathrm{O}$ anterior pode contribuír a explicar a diverxencia gradual que se produciu entre os movementos catalán e provenzal logo dunha simultaneidade inicial na que ambos se entrecruzaban, ademais de servir para situar a fundación das Irmandades da Fala dentro da dinámica do rexionalismo e nacionalismo galegos e na cronoloxía do desenvolvemento do rexionalismo e o nacionalismo en Europa ${ }^{12}$.

\footnotetext{
${ }^{12} \mathrm{O}$ meu agradecemento aos estudantes auxiliares da Study Platform on Interlocking Nationalisms («Plataforma de Estudo dos Nacionalismos Entrelazados» [SPIN], https://spinnet.eu/), cuxo laborioso rexistro de datos deu como resultado todas as liñas dos mapas que se reproducen aquí e en http://romanticnationalism.net.
} 


\section{REFERENCIAS BIBLIOGRÁFICAS}

Anderson, Benedict (2005): Under Three Flags: Anarchism and the Anti-colonial Imagination, London, Verso.

CONNOR, Walker (1994): Ethnonationalism: The Quest for Understanding, Princeton, NJ, Princeton University Press.

Hroch, Miroslav (2005): Das Europa der Nationen: die moderne Nationsbildung im europäischen Vergleich, Göttingen, Vandenhoeck \& Ruprecht.

LAJOSI, Krisztina / Andreas STYNEN (eds.) (2015): Choral Societies and Nationalism in Europe, Leiden, Brill.

LATOUR, Bruno (2005): Reassembling the Social: An Introduction to Actor-Network-Theory, Oxford, Oxford University Press.

LEERSSEN, Joep (2006): «Nationalism and the cultivation of culture», Nations and Nationalism, 12:4, 559-578.

LEERSSEN, Joep (2015): «The nation and the city: urban festivals and cultural mobilization», Nations and Nationalism, 21:1, 2-20.

LEERSSEN, Joep (2016a): «Cúchulain in the general post office: Gaelic revival, Irish rising», Journal of the British Academy, 4, 138-167.

LeErssen, Joep (2016b): «Gods, Heroes and Mythologists: Romantic Scholars and the Pagan Roots of Europe's Nations», History of Humanities, 1, 71-100.

LeERSSen, Joep (ed.) (2018): Encyclopedia of Romantic Nationalism in Europe, Amsterdam, Amsterdam University Press.

STUTJE, Klaas (2019): Campaigning in Europe for a Free Indonesia: Indonesian Nationalists and the Worldwide Anticolonial Movement, 1917-1931, Copenhagen, NIAS Press. 